Article

\title{
Redox-Mediated Polymer Catalyst for Lithium-Air Batteries with High Round-Trip Efficiency
}

\author{
Min-Cheol Kim ${ }^{1}$, Jung Hyun Song ${ }^{2}$, Young-Woo Lee ${ }^{3, *(D)}$ and Jung Inn Sohn ${ }^{1, *}$ \\ 1 Division of Physics and Semiconductor Science, Dongguk University-Seoul, Seoul 04620, Korea; \\ mcnet618@dongguk.edu \\ 2 Division of Japanese Studies, Dongguk University-Seoul, Seoul 04620, Korea; songjh@dongguk.edu \\ 3 Department of Energy Systems, Soonchunhyang University, Asan 31538, Korea \\ * Correspondence: ywlee@sch.ac.kr (Y.-W.L.); junginn.sohn@dongguk.edu (J.I.S.)
}

Received: 27 November 2020; Accepted: 16 December 2020; Published: 17 December 2020

\begin{abstract}
Lithium-air batteries (LABs) continue to receive attention as a promising power source because they possess a high theoretical energy density of $3436 \mathrm{Wh} \mathrm{L}^{-1}$. However, the remaining $\mathrm{Li}_{2} \mathrm{O}_{2}$ resulting from the irreversible decomposition of $\mathrm{Li}_{2} \mathrm{O}_{2}$ during the charge process is one of the key challenges so as to address the deterioration of the cycling performance of LABs. In this study, we propose and report a redox-mediated polymer catalyst (RPC) as a cathode catalyst being composed of LiI and poly (vinylidene fluoride-co-hexafluoropropylene) (PVDF-HFP) with multi-wall carbon nanotubes (MWCNTs) as the cathode material. In the RPC, iodine molecules are chemically combined with the PVDF-HFP chain. The as-prepared RPC exhibits increased cycling performance by $194 \%$ and decreased overpotential by $21.1 \%$ at $0.1 \mathrm{~mA} \mathrm{~cm}^{-2}$ compared to the sample without LiI molecules. Furthermore, these results suggest that the RPC consisting of a polymer chain and redox mediators will be extensively utilized as highly efficient catalysts of LABs.
\end{abstract}

Keywords: PVDF-HFP; LiI; redox-mediated polymer catalyst; lithium-air batteries

\section{Introduction}

The lithium-air batteries (LABs) continue to be of considerable interest for their potential use as building blocks of energy storage devices that require the high energy density due to their excellent theoretical energy density of $3436 \mathrm{Wh} \mathrm{L}^{-1}$ compared to the lithium-ion batteries (1015 Wh L $\left.{ }^{-1}\right)$ [1-4]. However, despite the promising energy storage capabilities and significant progress being made in LABs, further improvements and developments of LABs are needed to satisfy the requirements of industrial applications for successful commercialization. Particularly, the low decomposition rate of $\mathrm{Li}_{2} \mathrm{O}_{2}$ occurring during the charge process has been arguably considered as one of the most important challenges so as to address the deterioration of the device performance [5-8]. In general, when the LABs are ideally operated, the $\mathrm{Li}_{2} \mathrm{O}_{2}$ produced during the discharge process accompanied by oxygen reduction reaction (ORR) is completely decomposed during the charging process accompanied by oxygen evolution reaction (OER). Recent studies have recognized that the round-trip efficiency of LABs is closely related to the rate of decomposition of $\mathrm{Li}_{2} \mathrm{O}_{2}$ produced during the discharge process $[9,10]$. It has been reported that catalyst-free LABs exhibit serious performance degradation that arises from low OER activities leading to the failure of efficient decomposition of $\mathrm{Li}_{2} \mathrm{O}_{2}$, and hence resulting in fading of the round-trip efficiency [11,12]. Thus, to address issues of the irreversible reactions associated with $\mathrm{Li}_{2} \mathrm{O}_{2}$ at the cathode, tremendous efforts have been directed towards the improvement of OER performance by proposing and developing a variety of catalysts. Among various catalysts studied to date, it has been demonstrated that solid-type catalysts based on precious metals and oxides, such as $\mathrm{Pt}, \mathrm{Au}, \mathrm{RuO}_{2}$, and $\mathrm{MnO}_{2}$, can effectively decompose $\mathrm{Li}_{2} \mathrm{O}_{2}$ due to their high OER 
activity, although the price of high precious metal catalysts and a lack of contact area between the catalyst and $\mathrm{Li}_{2} \mathrm{O}_{2}$ are considered limits of solid-type catalysts [13-16]. Alternatively, it has been also demonstrated that liquid-type catalysts could improve OER performance by adding redox meditators (RMs), such as tetrathiaflvalene (TTF), iron phthalocyanine (FePc) and iodine molecules, into liquid electrolytes $[17,18]$. The molecular TTF, FePc, and iodine can move and diffuse unrestrictedly within liquid electrolytes, so they can be capable of facilitating favorable reactions by effectively providing the high catalytic active sites, which are a key requirement to solve the significant limitation of the solid-type catalysts suffering from a comparatively low contact area between the $\mathrm{Li}_{2} \mathrm{O}_{2}$ and the catalyst. As a result, the liquid-type catalyst would enable to induce high OER performance of LABs even with a small amount of RM contents. However, a crossover phenomenon has been reported to be an issue of the liquid-type catalysts, in which the RMs that pass to the anode cause a side reaction with the $\mathrm{Li}$ metal $[19,20]$, because of the unrestricted movement feature of the RMs that they can spread anywhere inside the cell. Thus, even if the solid- and liquid-type catalysts have been extensively investigated and developed, the need for study of more stable and more efficient catalysts still remains.

In this regard, redox-mediated polymer catalysts (RPCs), in which the polymer and RMs are chemically bonded, have been recently proposed and received considerable attention [21]. Such the RPCs can be expected to enable bi-functional materials capable of simultaneously performing the role of catalyst and binder. First, because the RPC represents the properties of polymer, it can be used like a binder by mixing the RPC evenly with multi-wall carbon nanotubes (MWCNTs) as cathode materials. By using the RPC as a binder, the RPC can be uniformly coated throughout the MWCNT, so it has an advantage of maximizing catalytic active sites. The second feature is that the RMs are chemically bonded with a polymer chain. Thus, the movement of RM over to the anode can be prevented, thereby effectively suppressing cross phenomena in the liquid-type catalysts. Consequently, if the performance of RPCs as catalysts could be further improved, the RPC with a clear differentiation from solid-type and liquid-type catalysts is considered to be a potential catalytic material.

Herein, we report a new polymer-based catalytic material candidate consisting of a pair of poly (vinylidene fluoride-co-hexafluoropropylene) (PVDF-HFP) as a polymer and molecular iodine as a RM (referred as "PH-Iodine RPC"). Compared with the polyvinylidene fluoride (PVDF), the incorporation of HFP groups provide the improved properties of PVDF-HFP better properties, such as higher Li salt solubility, lower crystallinity, greater free volume, and better mechanical strength [22]. Additionally, the iodine in the PH-Iodine RPC sample forms a chemical bond with the fluorine presented at the end of the PVDF chain. Moreover, since the HFP group can provide a relatively large amount of fluorine content, there is a possibility that PVDF-HFP can be used as a polymer to increase the concentration of iodine within the RPC. Therefore, we have identified the possibility of the PH-Iodine RPC as a new catalyst candidate for LABs through structural and electrochemical analysis.

The PH-Iodine RPC was mixed with MWCNTs and then was fabricated as the cathode for the LABs by a spray casting method. The prepared electrodes can evenly coat the surface of MWCNTs with the PH-Iodine RPC sample to maximize the electrochemical active site for electrochemical reactions. The iodine presented inside the PH-Iodine RPC sample can decompose the discharge product $\mathrm{Li}_{2} \mathrm{O}_{2}$ through the reaction of Equations (1) and (2) (Figure 1) [23].

$$
\begin{gathered}
\mathrm{RM} \rightarrow \mathrm{RM}^{\mathrm{ox}}+\mathrm{e}^{-} \quad \text { (Electrochemical oxidation) } \\
\mathrm{Li}_{2} \mathrm{O}_{2}+2 \mathrm{RM}^{\mathrm{ox}} \rightarrow \mathrm{O}_{2}+2 \mathrm{RM}+2 \mathrm{Li}^{+} \text {(Chemical reduction) }
\end{gathered}
$$




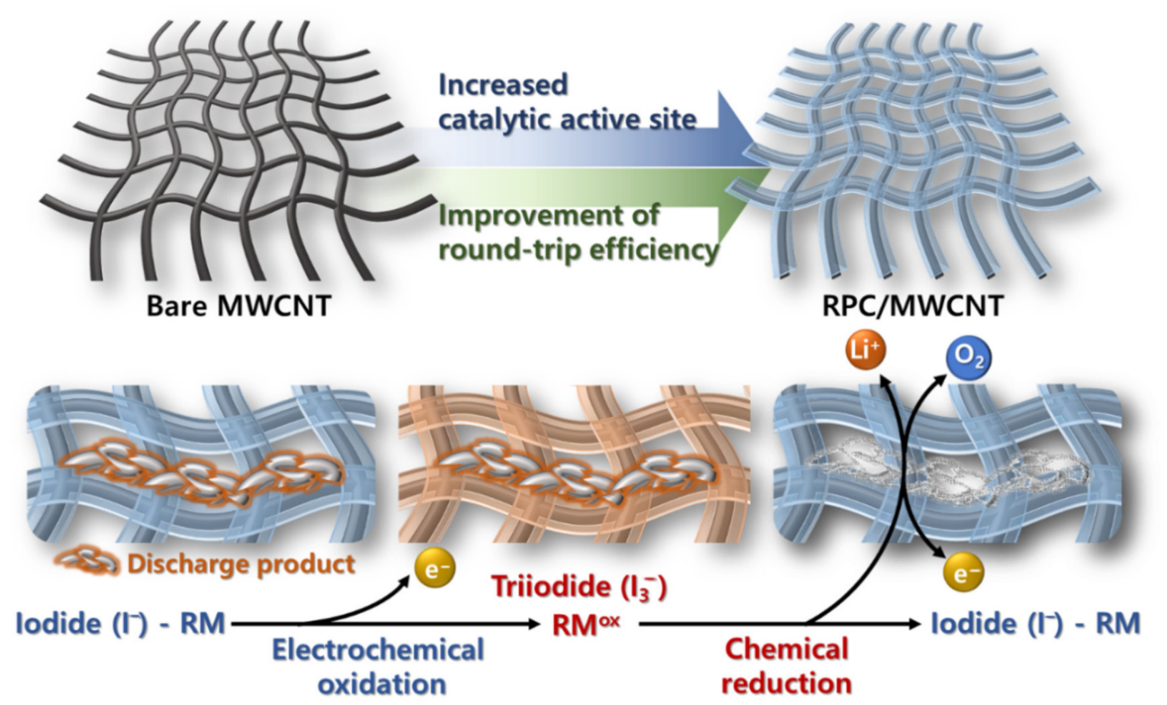

Figure 1. Schematic of the redox-mediated polymer catalyst (RPC) as a cathode catalyst for lithium-air batteries (LABs).

To analyze the crystallographic structure and the atomic binding state of the PH-Iodine RPC, X-ray photoelectron spectroscopy (XRD) and X-ray photoelectron spectroscopy (XPS) were conducted. Furthermore, the field-emission scanning electron microscope (FE-SEM) and the energy dispersive X-ray spectroscopy (EDX) were used to verify the morphological analysis of electrode surface and the content of iodine. To compare the electrochemical performance of the synthesized sample, the sample without iodine (Only PH) was synthesized, and the electrochemical analysis of the samples was conducted through a charge-discharge test. As a result of electrochemical analysis, the PH-Iodine RPC sample achieved $235 \%$ improvement in cycle characteristics and $9.01 \%$ improvement in round-trip efficiency over the Only PH sample.

\section{Results and Discussion}

In order to investigate structural properties of the samples, the XRD patterns were obtained as shown in Figure 2a. For the Only PH sample, the dominant XRD peaks were observed at $18.4^{\circ}$, $20.3^{\circ}$, and $39.5^{\circ}$, which corresponded to the $\alpha-, \beta-$, and $\gamma$-phases of the PVDF-HFP, respectively [24]. Compared to the Only PH sample, the PH-Iodine RPC sample exhibited the relative decrease in intensities of the XRD peaks. The crystallinity of the PH-Iodine sample might be reduced because the iodine interferes with interaction between chains of the PVDF-HFP during crystallization. It has been reported that the crystallinity of the polymer can be decrease during crystallization of the polymer, when a polymer is mixed with substances, such as oxides and plasticizers [25]. Accordingly, it is implied that the reduction in crystallinity of the PH-Iodine RPC sample is the result of the well-mixed state of the PVDF-HFP and the iodine within the PH-Iodine RPC sample. To further analyze the uniformity of the PH-Iodine RPC sample, SEM and EDX measurements were carried out as shown in Figure 2c-e, respectively. The SEM image of Figure 2c shows the surface image of the electrode loaded with MWCNTs using the PH-Iodine RPC as a binder on the carbon paper. It can be seen from the EDX analysis results of Figure 2d,e that signals of carbon and iodine on the electrode surface are displaced in the same spot. These results confirmed that the prepared electrodes were uniformly mixed with the MWCNTs and the PH-Iodine RPC. In addition, XPS analysis of the PH-Iodine RPC sample was conducted to identify chemical structure in which the PVDF-HFP and the iodine are chemically bonded. According to the XPS spectra shown in Figure 2b, the PH-Iodine RPC sample consisted of iodide $\left(\mathrm{I}^{-}\right)$and iodine $\left(\mathrm{I}_{2}\right)$. Of the two iodine species, the chemically bonded iodide at the end of the PVDF-HFP chain contributes directly to the decomposition reaction of $\mathrm{Li}_{2} \mathrm{O}_{2}$ during the charging 
process, while the iodine remains physically adsorbed inside the PVDF-HFP chain. The mechanism of the decomposition of $\mathrm{Li}_{2} \mathrm{O}_{2}$ based on iodide can be described by the following steps [26]:

$$
\begin{array}{cc}
3 \mathrm{I}^{-} \rightarrow \mathrm{I}_{3}^{-}+2 \mathrm{e}^{-} & \text {(Electrochemical oxidation) } \\
\mathrm{I}_{3}{ }^{-}+\mathrm{Li}_{2} \mathrm{O}_{2} \rightarrow 2 \mathrm{Li}^{+}+\mathrm{O}_{2}+3 \mathrm{I}^{-} & \text {(Chemical reduction) }
\end{array}
$$
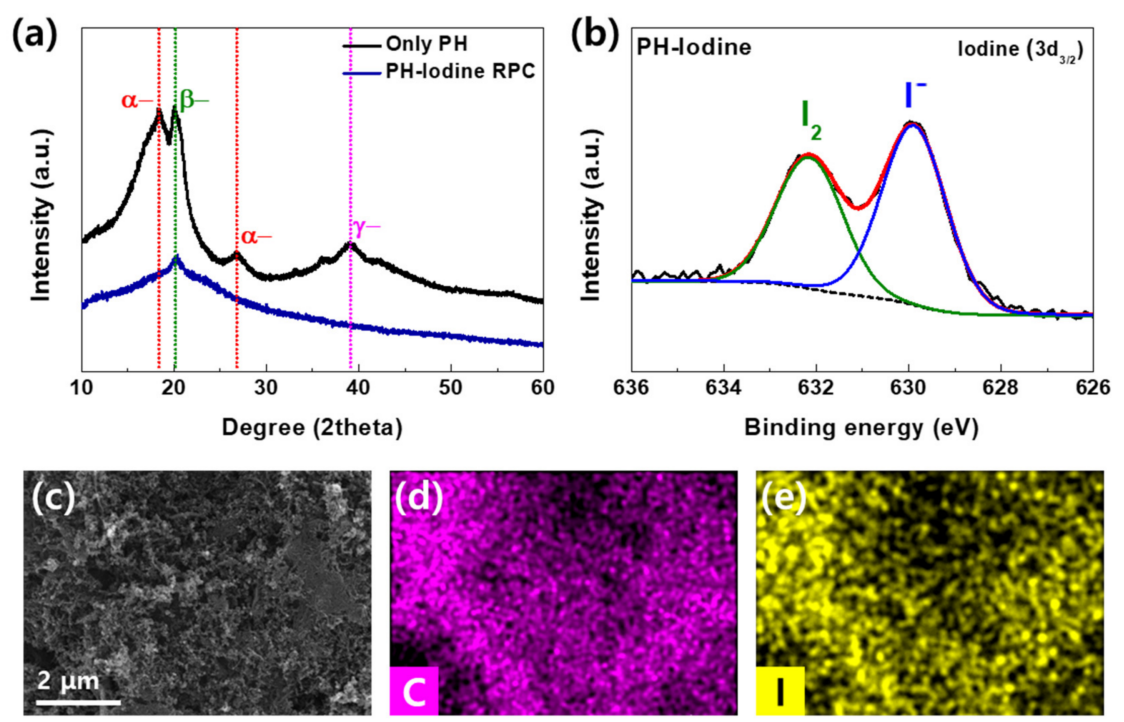

Figure 2. Structural analysis of the samples. (a) XRD patterns of the samples. (b) XPS spectra of I 3d for the PH-Iodine RPC sample. (c) FE-SEM and (d,e) EDX mapping images of the electrode of the PH-Iodine RPC sample.

Even so, it is not that iodine does not contribute to the chemical reactions. Note that based on our previously reported result [21], it was revealed that during the cycle, the state of iodine can be changed into the iodide $\left(\mathrm{I}^{-}\right)$state by the reduction reaction, contributing to the catalytic reaction.

Figure 3 shows the charge-discharge test performed at a current density of $100 \mu \mathrm{A} \mathrm{cm}^{-2}$ to evaluate the electrochemical performance of samples. The theoretical voltage of charging and discharging of LABs is known as $2.96 \mathrm{~V}$ (vs. $\mathrm{Li} / \mathrm{Li}^{+}$). Figure $3 \mathrm{a}-\mathrm{c}$ show the charge-discharge graph of PH-Iodine RPC and Only PH samples, in which both the samples exhibit a difference between the charge and discharge curve due to the overpotential. In particular, the voltage of the charge curve associated with the OER performance was measured relatively high. However, it is clearly observed that the overpotential of the PH-Iodine RPC sample showed approximately $200 \mathrm{mV}$ lower than the Only PH sample. The reduced overpotential of the PH-Iodine RPC sample indicated that the iodide acted as the OER catalyst. In relation to the mechanism of the RM, in the Figure 3a-c graph, the flat region appeared near $3.45 \mathrm{~V}$ for the PH-Iodine RPC sample, which is associated with an electrochemical oxidation reaction in which the iodide $\left(\mathrm{I}^{-}\right)$is oxidized to triiodide $\left(\mathrm{I}_{3}{ }^{-}\right)$as shown in Equation (3) [27]. Subsequently, the flat region shown at $3.6 \mathrm{~V}$ was the reaction in which the generated $\mathrm{I}_{3}{ }^{-}$decomposed $\mathrm{Li}_{2} \mathrm{O}_{2}$, producing I- by chemical reduction as shown in Equation (4) [28]. Figure 3d shows a graph of the differential capacity vs. voltage after five cycles of each sample. The differential capacity of the PH-Iodine RPC sample showed sharp peaks at $3.46 \mathrm{~V}, 3.58 \mathrm{~V}$ and $3.78 \mathrm{~V}$, corresponding to the flat regions confirmed in the charging curve. According to the literature [29-31], the peak shown at $3.46 \mathrm{~V}$ was associated with the electrochemical oxidation reaction of the RM, while the peak shown at $3.58 \mathrm{~V}$ was associated with the decomposition reaction of amorphous $\mathrm{Li}_{2} \mathrm{O}_{2-\mathrm{x}}$. The peak observed at $3.78 \mathrm{~V}$ can be interpreted in relation to the reaction in which crystalline $\mathrm{Li}_{2} \mathrm{O}_{2}$ was decomposed. On the other hand, the peak of the Only PH sample was observed at $4.0 \mathrm{~V}$, which was relatively higher than that of the PH-Iodine RPC sample, which means the high overpotential identified in the charge-discharge graph. 
These findings suggest that for the Only PH sample, the accumulation of $\mathrm{Li}_{2} \mathrm{O}_{2}$ that had not been sufficiently decomposed during the charging process was accelerated. As a result, the accumulation of $\mathrm{Li}_{2} \mathrm{O}_{2}$ inside the cathode could cause a negative effect that gradually increased the overpotential during the cycling process. Figure $3 e$ shows the terminating voltage vs. cycle graph, exhibiting the change in overpotential described above. For the Only $\mathrm{PH}$ sample, it can be seen that the charge terminating voltage increased to $4.5 \mathrm{~V}$, which is the cut-off voltage after 36 cycles. The charge terminating voltage at $4.5 \mathrm{~V}$ suggests that the decomposition rate of $\mathrm{Li}_{2} \mathrm{O}_{2}$ was significantly reduced within the charging process. It can also be seen that the discharge terminating voltage decreased rapidly from the point when the charging termination voltage reached $4.5 \mathrm{~V}$. These results indicate that if the amount of $\mathrm{Li}_{2} \mathrm{O}_{2}$ remaining inside the cathode increased above a certain level, this could cause the following serious problems for the LAB's system. First, there was an undesirable decrease in mass transfer of $\mathrm{O}_{2}$ gas required for a reaction during the discharge process. In general, the chemical reaction rate is closely related to the concentration and mobility of the reactant [32]. As mentioned above, if $\mathrm{Li}_{2} \mathrm{O}_{2}$ accumulates to a certain level inside the cathode, the $\mathrm{Li}_{2} \mathrm{O}_{2}$ will block the pathway through which the $\mathrm{O}_{2}$ gas would transfer. Thus, the reduced mobility and concentration of $\mathrm{O}_{2}$ gas caused an increase in overpotential during the discharge process. The second is that the electrons were not favorably transferred for the effective $\mathrm{Li}_{2} \mathrm{O}_{2}$ generation reaction because the accumulated $\mathrm{Li}_{2} \mathrm{O}_{2}$ has non-conductive properties. Thus, this resulted in an increase in overpotential during the discharge process.
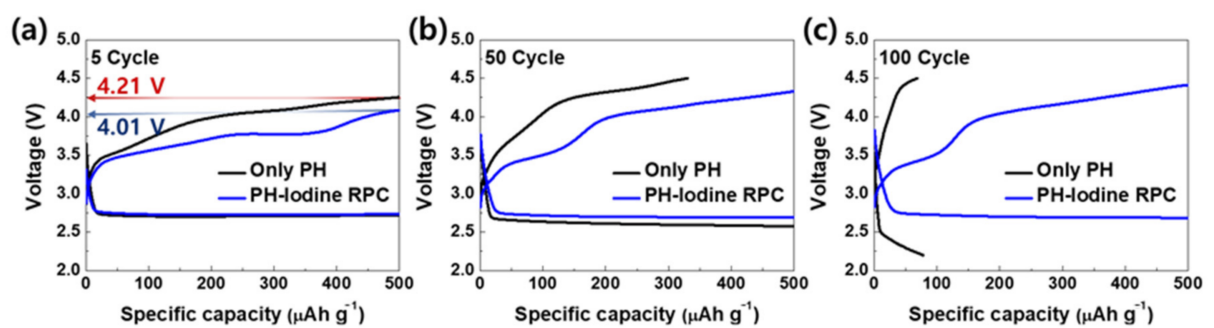

(d)

(e)
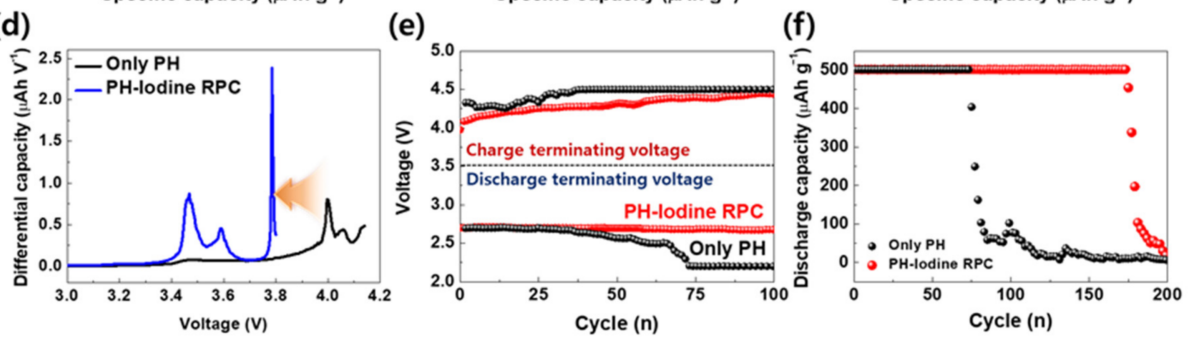

Figure 3. Electrochemical performance of the samples. Plots of voltage vs. specific capacity measured at $100 \mu \mathrm{A} \mathrm{cm}^{-2}$ of (a) 5 cycle, (b) 50 cycle and (c) 100 cycle. (d) Plots of differential capacity vs. voltage for the samples. (e) The charge-discharge terminating voltage vs. cycle plot for the samples. (f) Comparison of discharge capacity vs. cycle number for the samples.

On the other hand, the terminating voltage vs. cycle graph of the PH-Iodine RPC sample shows superior ORR characteristics with a high discharge terminating voltage even after 120 cycles. In addition, it is also observed that the charge terminating voltage of the PH-Iodine RPC sample was relatively low. Further, ex-situ FE-SEM image of the electrode surface of each sample measured after five cycles clearly distinguishes the difference between the samples. Compared to the PH-Iodine RPC sample, the Only PH sample showed that the MWCNTs were covered with a significant amount of materials assumed to be $\mathrm{Li}_{2} \mathrm{O}_{2}$ after five cycles charging, as shown in Figure 4a-c. The electrochemical analysis and ex-situ FE-SEM image analysis results are consistent with the excellent catalytic activity of the PH-Iodine RPC samples shown in Figure 3. Consequently, the cycle performance of the PH-Iodine RPC sample achieved about 235\% higher than those of the Only PH sample (Figure 3f). 

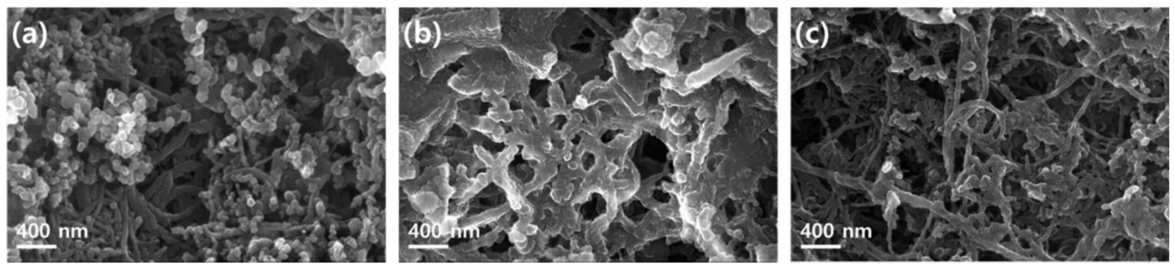

Figure 4. FE-SEM images of the samples: (a) before cell test, (b) after 5 cycle charging the Only PH sample, (c) after 5 cycle charging the PH-Iodine RPC sample.

The high-rate performance of samples was performed at current densities ranging from 20 to $500 \mu \mathrm{A} \mathrm{cm}^{-2}$ (Figure $5 \mathrm{a}, \mathrm{b}$ ). At the highest current density of $500 \mu \mathrm{A} \mathrm{cm}^{-2}$, the charge process of the Only $\mathrm{PH}$ sample was urgently terminated, not reaching a specific capacity of $500 \mu \mathrm{Ah} \mathrm{cm}{ }^{-2}$. It is assumed that a serious round-trip efficiency drop has occurred as the overpotential sharply increases at a fairly high current density. Figure $5 \mathrm{c}$ shows the calculated round-trip efficiency of samples calculated by the expression below.

Round-trip efficiency $=($ Discharge energy density/Charge energy density $) \times 100$
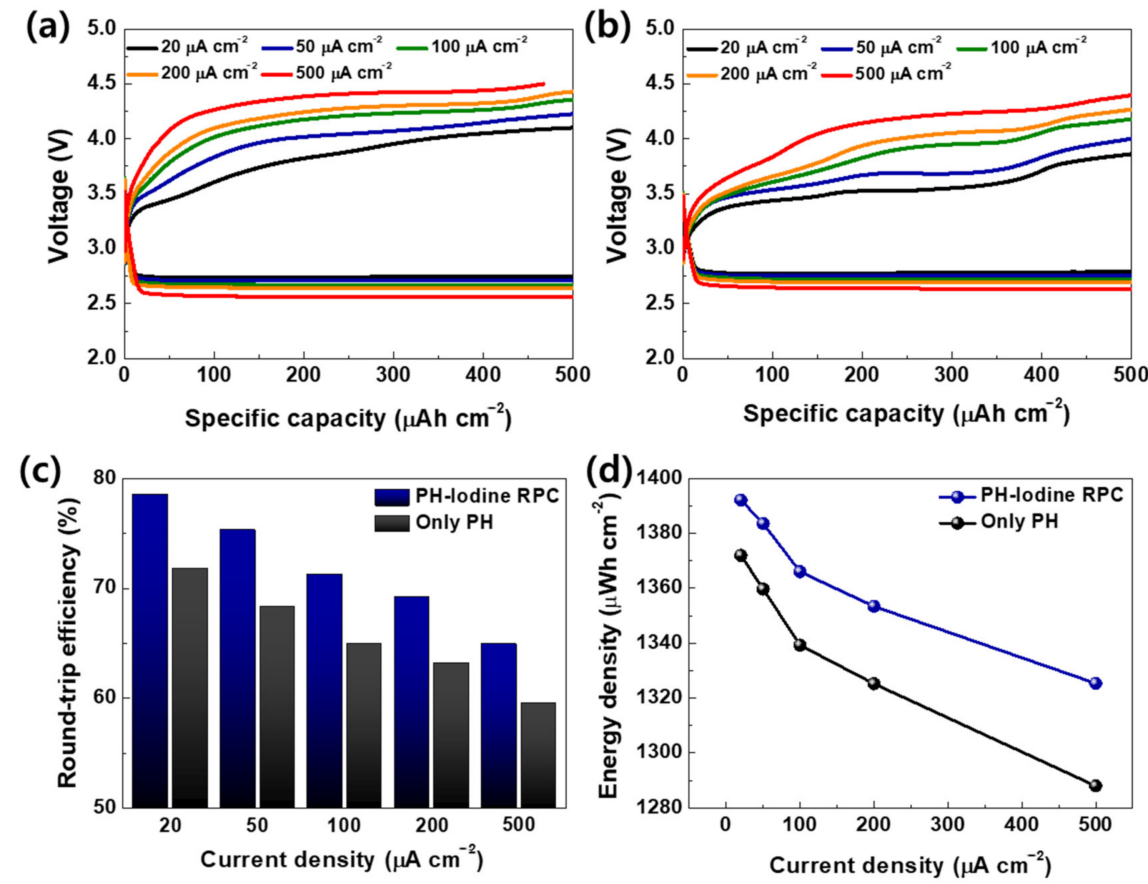

Figure 5. High-rate performance of the samples. Plots of voltage vs. specific capacity measured at different current densities of (a) Only PH and (b) PH-Iodine RPC samples. (c) Comparison of round-trip efficiency for the samples. (d) Plots of energy density vs. current density for the samples.

The PH-Iodine RPC sample showed a round-trip efficiency of higher current density than the Only $\mathrm{PH}$ sample and a difference of $5.36 \%$ at the current density of $500 \mu \mathrm{A} \mathrm{cm}^{-2}$ (Figure 5c). In addition, the increased overpotential could decrease the energy density, i.e., discharge capacity $x$ voltage, due to the decreased terminating voltage. Therefore, according to Figure $5 \mathrm{~d}$, which shows the energy densities of samples, the energy densities of the PH-Iodine RPC sample were measured higher than the energy densities of the Only PH sample at all current densities. It is known that RPC catalysts only affect OER performance. However, excellent OER performance can prevent excessive accumulation of $\mathrm{Li}_{2} \mathrm{O}_{2}$ in cathode electrodes because it can facilitate the decomposition of $\mathrm{Li}_{2} \mathrm{O}_{2}$. As a result, the enhanced mass transfer of the reactants during the discharge process induces improved energy density. 


\section{Materials and Methods}

\subsection{Preparations of Redox-Mediated Polymer Catalyst (RPC)}

To prepare RPCs for LABs, $0.5 \mathrm{~g}$ of poly(vinylidene fluoride-co-hexafluoropropylene) (PVDF-HFP, average $\mathrm{M}_{\mathrm{w}} \sim 400,000$, Aldrich, Saint louis, MO, USA) was dissolved in $9.5 \mathrm{~g}$ of N-Methyl-2-pyrrolidone (NMP, 99.5\%, Samchun, Seoul, Korea) by stirring on a $50{ }^{\circ} \mathrm{C}$ hot plate for $12 \mathrm{~h}$. Then $0.5 \mathrm{~g}$ of Lil (99\%, Aldrich) was added to the mixture and then continued to stir for $24 \mathrm{~h}$.

\subsection{Fabrication of Electrodes}

The mixture solution of multi-wall carbon nanotubes (MWCNTs, Graphene supermarket, Ronkonkoma, NY, USA, $70 \mathrm{wt} . \%)$ as a cathode material, Super P (20 wt.\%) as a conductive agent, RPCs $(10 \mathrm{wt} . \%)$ as a binder and catalyst, and $50 \mathrm{~mL}$ of ethanol as solvent was ultrasonically treated for $4 \mathrm{~h}$. Then, the mixture solution was uniformly sprayed on the carbon paper at $80^{\circ} \mathrm{C}$. The prepared electrode was dried for $24 \mathrm{~h}$ in a $50^{\circ} \mathrm{C}$ oven to remove the remaining ethanol (PH-Iodine). For comparison of samples, a sample using PVDF-HFP instead of RPCs was prepared (Only PH).

\subsection{Materials Characterization}

To investigate the crystal structure of the samples, an X-ray diffractometer (XRD, Bruker, Massachusetts, MA, USA, D2 Phase system) measurements were carried out at $40 \mathrm{kV}$ and $100 \mathrm{~mA}$ with an X-ray source of $\mathrm{Cu} K \alpha(\lambda=0.15418 \mathrm{~nm})$. The chemical composition and state of the samples were assessed using an X-ray photoelectron spectroscopy (XPS, Thermo VG Scientific, Massachusetts, MA, USA, k-alpha). The surface morphology of the electrodes was examined by a field-emission scanning electron microscope (FE-SEM, Germini 300, ZEISS, Oberkochen, Germany).

\subsection{Cell Fabrication and Measurement}

The electrochemical cells for the LABs were assembled using the prepared electrode as a cathode, polyethylene (Celgard 2400, Celgard, North Carolina, NC, USA) as a separator, and lithium metal (FMC Corporation, Philadelphia, PA, USA) as an anode. $200 \mu \mathrm{L}$ of 1M LiTFSI in tetraethylene glycol dimethyl ether (TEGDME, Aldrich) was added as an electrolyte. The fabricated cell was aged for $1 \mathrm{~h}$ in an $\mathrm{O}_{2}$ gas-saturated case prior to electrochemical measurments. The cell test was evaluated using a multichannel battery tester (WBCS3000L, Wonatech Co., Seoul, Korea) in the potential range of 2.2-4.5 V vs. $\mathrm{Li} / \mathrm{Li}^{+}$at different current densities from 20 to $500 \mu \mathrm{A} \mathrm{cm}{ }^{-2}$ at $25^{\circ} \mathrm{C}$.

\section{Conclusions}

We designed and successfully synthesized PH-Iodine RPCs as a cathode catalyst being composed of iodine and PVDF-HFP with MWCNTs for LABs. We showed that the chemical bonding between iodine molecules and PVDF-HFP prevents the crossover of RMs. Furthermore, we demonstrated that the uniformly dispersed bifunctional PH-Iodine RPC sample can act as both the binder and the catalyst. Compared to the Only PH sample in the absence of molecular iodine, the cycle performance of the PH-Iodine RPC sample achieved about 235\% higher than those of the Only PH sample. In addition, as a result of the reduced overpotential due to the favorable structural property of PH-Iodine RPC samples with wide catalytic active sites, the PH-Iodine RPC samples showed a 5.36\% improvement in round-trip efficiency compared to the Only PH sample. The role of iodine as a redox mediator in the polymer matrix was revealed based ex-situ XPS characterization. Consequently, it is expected the PH-Iodine RPC sample consisting of iodine and PVDF-HFP will be utilized as a promising catalyst for high-performance LABs.

Author Contributions: Conceptualization, M.-C.K. and Y.-W.L.; methodology, M.-C.K.; validation, M.-C.K., J.H.S. and Y.-W.L.; formal analysis, M.-C.K.; investigation, M.-C.K., J.H.S. and Y.-W.L.; resources, Y.-W.L. and J.I.S.; data curation, M.-C.K.; writing-original draft preparation, M.-C.K. and J.I.S.; writing-review and editing, M.-C.K., J.H.S., Y.-W.L., and J.I.S.; visualization, M.-C.K.; supervision, M.-C.K. and J.I.S.; project administration, 
Y.-W.L. and J.I.S.; funding acquisition, M.-C.K. and J.I.S. All authors have read and agreed to the published version of the manuscript.

Funding: This research was supported by Basic Science Research Program through the National Research Foundation of Korea (NRF) funded by the Ministry of Education (NRF-2020R1I1A1A01061197). J.I.S. acknowledges that this work was supported by the Dongguk University Research Fund of 2018.

Conflicts of Interest: The authors declare no conflict of interest.

\section{References}

1. Bruce, P.G.; Freunberger, S.A.; Hardwick, J.-M. Tarascon, $\mathrm{Li}_{-} \mathrm{O}_{2}$ and Li-S Batteries with High Energy Storage. Nat. Mater. 2012, 11, 19-29. [CrossRef]

2. Grande, L.; Paillard, E.; Hassoun, J.; Park, J.-B.; Lee, Y.-J.; Sun, Y.K.; Passerini, S.; Scrosati, B. The Lithium/Air Battery: Still an Emerging System or a Practical Reality? Adv. Mater. 2015, 27, 784-800. [CrossRef]

3. Xu, S.; Yao, Y.; Guo, Y.; Zeng, X.; Lacey, S.D.; Song, H.; Chen, C.; Li, Y.; Dai, J.; Wang, Y.; et al. Textile Inspired Lithium-Oxygen Battery Cathode with Decoupled Oxygen and Electrolyte Pathways. Adv. Mater. 2018, 30, 1704907. [CrossRef]

4. Choi, W.; Kim, M.; Park, J.O.; Kim, J.-H.; Choi, K.; Kim, Y.S.; Kim, T.Y.; Ogata, K.; Im, D.; Doo, S.-G.; et al. Ion-channel Aligned Gas-blocking Membrane for Lithium-air Batteries. Sci. Rep. 2017, 7, 12037. [CrossRef]

5. Freunberger, S.A.; Chen, Y.; Peng, Z.; Griffin, J.M.; Hardwick, L.J.; Bardé, F.; Novák, P.; Burce, P.G. Reactions in the Rechargeable Lithium- $\mathrm{O}_{2}$ Battery with Alkyl Carbonate Electrolytes. J. Am. Chem. Soc. 2011, 133, 8040-8047. [CrossRef]

6. McCloskey, B.D.; Bethune, D.S.; Shelby, R.M.; Girishkumar, G.; Luntz, A.C. Solvents' Critical Role in Nonaqueous Lithium-Oxygen Battery Electrochemistry. J. Phys. Chem. Lett. 2011, 2, 1161-1166. [CrossRef]

7. Feng, N.; He, P.; Zhou, H. Critical Challenges in Rechargeable Aprotic Li-O $\mathrm{O}_{2}$ Batteries. Adv. Energy Mater. 2016, 6, 1502303. [CrossRef]

8. Han, J.; Guo, X.; Ito, Y.; Liu, P.; Hojo, D.; Aida, T.; Hirata, A.; Fujita, T.; Adschiri, T.; Zhou, H.; et al. Effect of Chemical Doping on Cathodic Performance of Bicontinuous Nanoporous Graphene for Li- $\mathrm{O}_{2}$ Batteries. Adv. Energy Mater. 2016, 6, 1501870. [CrossRef]

9. Shu, C.; Lin, Y.; Su, D. N-doped onion-like carbon as an efficient oxygen electrode for long-life $\mathrm{Li}^{-} \mathrm{O}_{2}$ battery. J. Mater. Chem. A 2016, 4, 2128-2136. [CrossRef]

10. Shao, Y.; Ding, J.; Xiao, J.; Zhang, J.; Xu, W.; Park, S.; Zhang, J.-G.; Wang, Y.; Liu, J. Making Li-Air Batteries Rechargeable: Material Challenges. Adv. Funct. Mater. 2013, 23, 987-1004. [CrossRef]

11. Bergner, B.J.; Schûrmann, A.; Peppler, K.; Garsuch, A.; Janek, J. A Mobile Catalyst for Rechargeable Li-O 2 Batteries. J. Am. Chem. Soc. 2014, 136, 15054-15064. [CrossRef]

12. Ko, Y.; Park, H.; Kim, J.; Lim, H.-D.; Lee, B.; Kwon, G.; Lee, S.; Bae, Y.; Park, S.K.; Kang, K. Biological Redox Mediation in Electron Transport Chain of Bacteria for Oxygen Reduction Reaction Catalysts in Lithium-Oxygen Batteries. Adv. Funct. Mater. 2019, 29, 1805623. [CrossRef]

13. Truong, T.T.; Liu, Y.; Ren, Y.; Trahey, L.; Sun, Y. Morphological and Crystalline Evolution of Nanostructured $\mathrm{MnO}_{2}$ and Its Application in Lithium-Air Batteries. ACS Nano 2012, 6, 8067-8077. [CrossRef]

14. Bhattacharya, P.; Nasybulin, E.N.; Engelhard, M.H.; Kovarik, L.; Bowden, M.E.; Li, X.S.; Gaspar, D.J.; Xu, W.; Zhang, J.-G. Dendrimer-Encapsulated Ruthenium Oxide Nanoparticles as Catalysts in Lithium-Oxygen Batteries. Adv. Funct. Mater. 2014, 24, 7510-7519. [CrossRef]

15. Jung, H.-G.; Jeong, Y.S.; Park, J.-B.; Sun, Y.-K.; Scrosati, B.; Lee, Y.J. Ruthenium-Based Electrocatalysts Supported on Reduced Graphene Oxide for Lithium-Air Batteries. ACS Nano 2013, 7, 3532-3539. [CrossRef]

16. McCloskey, B.D.; Scheffler, R.; Speidel, A.; Bethune, D.S.; Shelby, R.M.; Luntz, A.C. On the Efficacy of Electrocatalysis in Nonaqueous $\mathrm{Li}_{-} \mathrm{O}_{2}$ Batteries. J. Am. Chem. Soc. 2011, 133, 18038-18041. [CrossRef]

17. Chen, Y.; Freunberger, S.A.; Peng, Z.; Fontaine, O.; Bruce, P.G. Charging a $\mathrm{Li}-\mathrm{O}_{2}$ battery using a redox mediator. Nat. Chem. 2013, 5, 489-494. [CrossRef]

18. Kwak, W.-J.; Hirshberg, D.; Sharon, D.; Shin, H.-J.; Afri, H.; Park, J.-B.; Garsuch, A.; Chesneau, F.F.; Frimer, A.A.; Aurbach, D.; et al. Understanding the Behavior of Li-Oxygen Cells Containing LiI. J. Mater. Chem. A 2015, 3, 8855-8864. [CrossRef]

19. Kim, B.G.; Jo, C.; Shin, J.; Mun, Y.; Lee, J.; Choi, J.W. Ordered Mesoporous Titanium Nitride as a Promising Carbon-Free Cathode for Aprotic Lithium-Oxygen Batteries. ACS Nano 2017, 11, 1736-1746. [CrossRef] 
20. Adams, B.D.; Black, R.; Radtke, C.; Williams, Z.; Mehdi, B.L.; Browning, N.D.; Nazar, L.F. The Importance of Nanometric Passivating Films on Cathodes for Li-Air Batteries. ACS Nano 2014, 8, 12483-12493. [CrossRef]

21. Kim, M.-C.; Choi, S.; Kim, H.; Han, S.-B.; Moon, S.-H.; Kim, E.-S.; Kim, Y.-S.; Park, K.-Y. Polymeric redox mediator as a stable cathode catalyst for lithium- $\mathrm{O}_{2}$ batteries. J. Power Source 2020, 453, 227850. [CrossRef]

22. Wang, X.; Xiao, C.; Liu, H.; Huang, Q.; Fu, H. Fabrication and properties of PVDF and PVDF-HFP microfiltration membranes. J. Appl. Polym. Sci. 2018, 135, 46711. [CrossRef]

23. Sun, D.; Shen, Y.; Zhang, W.; Yu, L.; Yi, Z.; Yin, W.; Wang, D.; Huang, Y.; Wang, J.; Wang, D.; et al. A Solution-Phase Bifunctional Catalyst for Lithium-Oxygen Batteries. J. Am. Chem. Soc. 2014, 136, 8941-8946. [CrossRef]

24. Oh, W.J.; Lim, H.S.; Won, J.S.; Lee, S.G. Preparation of PVDF/PAR Composites with Piezoelectric Properties by Post-Treatment. Polymers 2018, 10, 1333. [CrossRef]

25. Guo, Q.; Han, Y.; Wang, H.; Xiong, S.; Sun, W.; Zheng, C.; Xie, K. Flame Retardant and Stable $\mathrm{Li}_{1.5} \mathrm{Al}_{0.5} \mathrm{Ge}_{1.5}\left(\mathrm{PO}_{4}\right)_{3}$-Supported Ionic Liquid Gel Polymer Electrolytes for High Safety Rechargeable Solid-State Lithium Metal Batteries. J. Phys. Chem. C 2018, 122, 10334-10342. [CrossRef]

26. Lim, H.-D.; Lee, B.; Zheng, Y.; Hong, J.; Kim, J.; Gwon, H.; Ko, Y.; Lee, M.; Cho, K.; Kang, K. Rational Design of Redox Mediators for Advanced $\mathrm{Li}^{-\mathrm{O}_{2}}$ batteries. Nat. Energy 2016, 1, 16066. [CrossRef]

27. Bruke, C.M.; Black, R.; Kochetkov, I.R.; Giordani, V.; Addison, D.; Nazar, L.F.; McCloskey, B.D. Implications of $4 \mathrm{e}^{-}$Oxygen Reduction via Iodide Redox Mediation in Li- $\mathrm{O}_{2}$ Batteries. ACS Energy Lett. 2016, 1, 747-756. [CrossRef]

28. Lim, H.-D.; Song, H.; Kim, J.; Gwon, H.; Bae, Y.; Park, K.-Y.; Hong, J.; Kim, H.; Kim, T.; Kim, Y.H.; et al. Superior Rechargeability and Efficiency of Lithium-Oxygen Batteries: Hierarchical Air Electrode Architecture Combined with a Soluble Catalyst. Angew. Chem. Int. Ed. 2014, 53, 3926-3931. [CrossRef]

29. Li, F.; Chen, J. Mechanistic Evolution of Aprotic Lithium-Oxygen Batteries. Adv. Energy Mater. 2017, 7, 1602934. [CrossRef]

30. Liu, T.; Leskes, M.; Yu, W.; Moore, A.J.; Zhou, L.; Bayley, P.M.; Kim, G.; Grey, C.P. Cycling Li-O 2 batteries via $\mathrm{LiOH}$ formation and decomposition. Science 2015, 350, 530-533. [CrossRef]

31. Dutta, A.; Ito, K.; Nomura, A.; Kubo, Y. Quantitative Delineation of the Low Energy Decomposition Pathway for Lithium Peroxide in Lithium-Oxygen Battery. Adv. Sci. 2020, 7, 2001660. [CrossRef]

32. Aurbach, D.; McCloskey, B.D.; Nazar, L.F.; Bruce, P.G. Advances in understanding mechanisms underpinning lithium-air batteries. Nat. Energy 2016, 1, 16128. [CrossRef]

Publisher's Note: MDPI stays neutral with regard to jurisdictional claims in published maps and institutional affiliations.

(C) 2020 by the authors. Licensee MDPI, Basel, Switzerland. This article is an open access article distributed under the terms and conditions of the Creative Commons Attribution (CC BY) license (http://creativecommons.org/licenses/by/4.0/). 